\title{
Economies of Scale in the Payment Card Market in Chile
}

Submitted 25/03/21, $1^{\text {st }}$ revision 10/04/21, $2^{\text {nd }}$ revision 30/04/21, accepted 25/05/21

\author{
Gonzalo Escobar Elexpuru1, Iván Valdés De la Fuente ${ }^{2}$
}

\begin{abstract}
:
Purpose: In recent years, the growth of credit and debit card transactions has increased significantly in quantity and volume. This work examines the existence of economies of scale in transaction processing, in a market with a vertically integrated.

Design/Methodology/Approach: it was constructed an econometric model to measure whether there are economies of scale in the commercial transactions with credit and debit cards. A data Panel technique was used to run the model.

Findings: The existence of a monopoly is not in itself a problem per se, what does create competition problems is the structure of that firm. After estimating the panel's data model indirectly from a cost function, this work determines the existence of economies of scale in the industry.

Practical Implications: The model shows the existence of economies of scale in transaction processing after the entry of new actors in all segments of the industry, which increases the competition in the market.

Originality/Value: This research contributes to the literature by estimating economies of scale in the payment card trading processing market in a two-sided market, which implies lower costs to make transaction with these cards and induces the entry of new actors to compete in a fringe of competitive firms.
\end{abstract}

Keywords: Economies of scale, two - sided markets, vertical integration.

JEL Classification: L42, L59.

Research type: Research paper.

${ }^{1}$ Universidad Andrés Bello, gonzalo.escobar@unab.cl;

${ }^{2}$ Universidad de Tarapacá, imvaldesd@academicos.uta.cl; 


\section{Introduction}

The credit and debit card market in Chile has shown significant growth in recent years, especially in the number of cards held by the public (cardholders) as well as in the number of transactions made, which have shown a growth of $102 \%$ for the period January 2013 to May 2020. This situation is explained by several changes in the market, which have contributed to this result. An example of this is the case of the introduction and massification of the Cuenta Rut by Banco Estado and the acquisition by traditional banking of the client portfolio of secured credit cards, which were issued by retail.

Also, one of the characteristics presented by this industry in Chile is the existence of a single network until that date intended for the cards' operation. A firm that has the status in its shareholding structure, if the central banks of the country constitute it, entities that at the same time have delegated the role of the acquirer of the shops, which, in addition to its functions of capturing, processing, and authoring these operations, give you a position to be a vertically integrated signature. This situation has been showing changes during the last half of 2018. One of the principal shareholders of the network makes the first decision to terminate its contract with the network so that the latter performs in its name the functions of the acquirer of the shops, and second sell its shareholding in the network, which triggers a significant change in the structure of the market, as the three-pointed scheme prevailing in the industry disappears, transitioning to a four-pointed scheme. Simultaneously, the entry of other networks to operate in the market could imply an increase in the degree of competition in the industry (El Mostrador, 2018; La Tercera, 2020).

The structural element that can underpin a single relevant actor in the industry is the possible existence of increasing yields at scale in production processes. In this context, this work aims to validate the existence of such economies of scale in the industry as a starting point to determine the existence of market power. To achieve this, it is based on a Cobb-Douglas-type production function, and the assumption of maximizing profits for a firm operating under imperfect competition, a situation that is not far from reality, estimating an econometric model that allows indirect determination of the coefficients of the underlying cost function, as Varian (1992).

As a result, it is obtained from January 2013 to May 2020, the existence of economies of scale. This work then aims to characterize the presence of yields at scales and simulate the average cost behavior for given production levels. Finally, this work is divided into four sections; where the first is intended to make a brief description of the two existing schemes for networks operating in these markets and carry out a review of the literature on the existence and estimation of economies of scale. A second chapter shows the development of the model, wherefrom a Cobb-Douglas production function, a cost function is indirectly estimated for the signature. Subsequently, the econometric work is carried out, estimating the corrected model from a self-correlation problem, indirectly obtaining the parameters of the cost function, concluding the existence of economies of scale in the industry. 


\section{Literature Review}

In the model proposed by Rochet and Tirole (2002), they disclose a model of an imperfectly competitive credit card market, which identifies the existence of two types of networks, one of them open, which is known as a four-pointed scheme, and the second type of network, which is closed, and which is known as a three-pointed scheme. In the open schemes, as shown in Figure No. 1, a cardholder uses his card to make a transaction of a good or service in the trade, paying a $\mathrm{p}$ - price. For such a transaction, an amount of $\mathrm{p}+\mathrm{Pb}$ is debited from your account, where PB represents a commission charged by the issuing bank to your cardholder for the use of the card.

On the other hand, the issuing bank transfers $p-a^{B}$ to the network, where $a^{B}$ represents a fee charged on the bankside related to the cardholder. For its part, the network transfers $\mathrm{p}-\mathrm{a}^{\mathrm{S}}$ to the acquiring bank, where $\mathrm{s}$ represents the fee charged next to the trade. Finally, it is credited to the merchant account at the acquiring bank p $\mathrm{p}^{\mathrm{S}}$, where $\mathrm{p}^{\mathrm{S}}$ corresponds to the Merchant discount, associated with the trade where the transaction is made (Merchant Discount corresponds to a percentage of the sales that the network charges merchants for processing each transaction made through payment cards).

It is, therefore, in this scheme, where it is possible to bring together multiple actors, such as banks, usually, where each can tend to specialize on one or both sides of the market, that is, as an issuer at the service of cardholders, or as an acquirer at the service of commerce. In this scheme, the system is structured around firms that own the brands, which are finally responsible for giving the issuance and acquisition licenses by their respective brands to the banks (Figure 1).

\section{Figure 1. Four-Point Scheme}

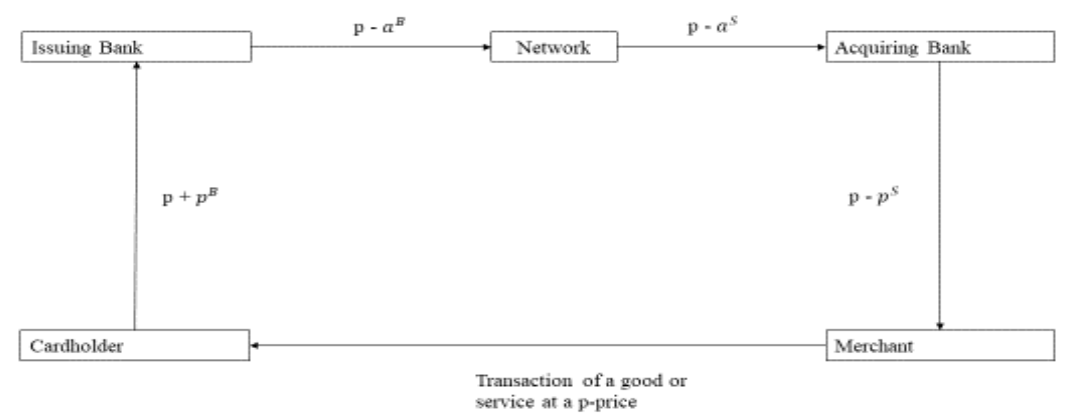

Source: Own creation.

In the closed schemes, as shown in Figure 2, a cardholder uses his card to make a purchase of a good or service in a merchant, paying a p price. For this transaction, an amount of $\mathrm{p}+\mathrm{p}^{\mathrm{B}}$ is debited from your account, where $\mathrm{p}^{\mathrm{B}}$ represents a commission that charges the network to the cardholder, a situation that is not explicitly charged in Chile. 
For its part, the network transfers to the bank account of the trade $p-p^{s}$, where $p^{s}$ corresponds to the Merchant discount. The Chilean case is represented by Transbank, where the platform is the only intermediary in card transactions between the cardholder and the merchant. Thus, in a three-pointed scheme, a firm that maximizes profits, and which additionally serves both sides of the market, that is, shops and cardholders, brings together in a single economic agent, the role of issuer and acquirer by a bank, which reaffirms the existence of vertical integration in the market.

\section{Figure 2. Three-Point Scheme}

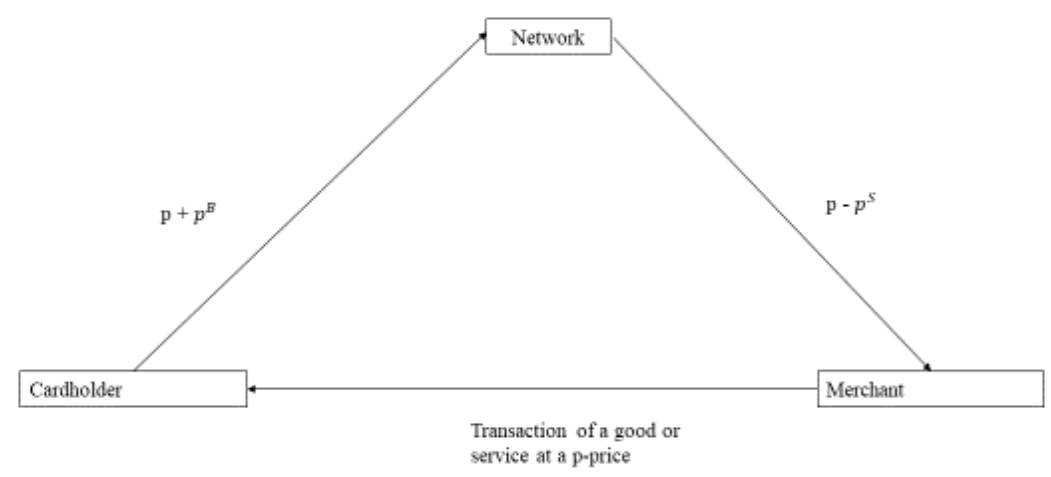

Source: Own creation.

Finally, from the figures above, it is possible to conclude that the card issuer maintains a direct relationship with the cardholders and is responsible for identifying and authorization the transactions' procedures and setting the limits of the credit. In return, you get commission income that has doubled in real terms is between January 2013 and May 2020 (CMF, 2020), and in the case of credit cards, in addition to interest, a product of the use of the card in the merchant. In turn, issuers face costs associated with processing transactions and costs associated with credit risk for credit cards.

In the acquirer's case, the acquirer is responsible for relating to the trade and is also responsible for processing the transactions and liquidating them to the issuer to pay the trader. However, it also typically develops transactional networks and platforms. The acquirer plays the marketer's role, motivating merchants to associate and accept the cards offered by the acquirer. It is also common for purchasers to fulfill the role of provider of transaction support services.

The merchant, on its side, pays the acquirer through a Merchant discount. In the case of four-point schemes, the acquirer remunerates the issuer by paying an exchange fee, which is historically fixed by the card marks, and if the market is competitive in the acquisition, the Merchant discount should converge at the marginal cost plus the exchange rate. 
Chile's credit card industry has been showing high dynamism in customer growth rates at both the credit card level and debit card customers, as shown in Figure 3. This market situation has not been accompanied by changes in the industrial organization of the sector. For more than two decades, there has been a single firm that delivers the acquiring service (business affiliation) and operator of the transaction network, thus showing a vertically integrated structure, which can generate direct effects on the existence and presence of economies of scale, a situation that has shown changes in recent periods.

Figure 3. Card Operations Evolution (Millions of operations: Jan 2008-May 2020)

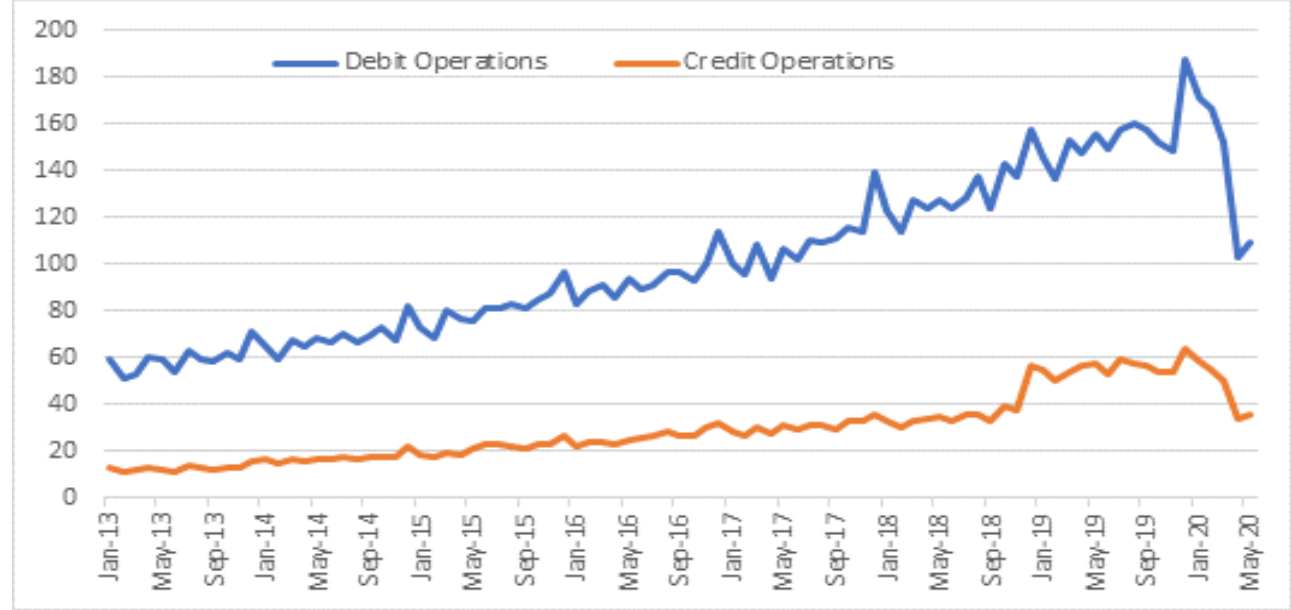

Source: Own elaboration based on www.sbif.cl.

One of the theoretical conditions for a market to respond to conditions of the competition is that the technology prevailing in the industry has consistent yields at scale, both in the market of productive factors and in the market of the final product, since firms will produce their optimum level in quantities such that they do not influence the equilibrium price according to Varian (1992). If a firm presents rising yields on its technology and there are no perfect information conditions, this firm can increase its market share and modify the structure of the market, as argued by Panzar (1989) and Amir (2002). Consequently, economies of scale in the technological process of a firm in the industry create the conditions for that firm to have a cost advantage over its competition and eventually seek consolidation as a dominant or market-leading firm. Taking all this to the extreme, the economy of scale underpins the argument for the existence of a natural monopoly, since, in this case, the optimal level of production co-indexes with total market demand, as proposed by Marchant (2007).

This process can be beneficial for consumers, as markets operate with imperfect information, since the price paid is relatively lower, reflecting the greater efficiency of the firm that presents economies of scale in its technological process, compared to that which would prevail in a competitive market, according to Marchant (2007). 
Econometric identification and estimation of economies of scale have been made using a trans logarithmic cost function on time series data, which relate plant sizes and technology-related variables, with an emphasis on cost elasticity at the primary production level, such as MacDonald and Ollinger (2000) and Ollinger et al. (2005). This functional form is flexible, and under certain constraints on its coefficients, can represent several functional forms and can be applied to multi-product signatures. Similarly, Akkemik (2009) estimates a cost function to determine the existence of economies of scale among others for the electricity generation industry in Turkey through a trans logarithmic cost function, like that performed by Aleaifar et al. (2014) for gas distribution in Switzerland, using panel data for 26 residential gas distribution firms.

About financial markets, the literature shows that economies of scale extend over different sizes of banks. Especially to larger banks, this is according to Beccalli, Anolli, and Borello (2015). This is demonstrated using the Stochastic Frontier Approach methodology, for a sample of 103 banks in Europe, with data from 2000 to 2001, something similar for Bolivian banking, especially in banks for microfinance and not for commercial banking, this by estimating a cost function through panel data for the years 1999 - 2004, this according to the work of Garron and Rocabado (2016). ${ }^{3}$

On the other hand, Kim (1986), starting with a trans logarithmic cost function for a multi-product firm, find a slight presence of economies of scale and scope for British Columbia credit unions, despite finding the existence of economies of scale in certain products, give clear evidence that they would not be in the presence of a natural monopoly, this from the work of Murray and White (1983). They determine this using cost as an independent variable. Among the control, variables are the price of inputs. On the other hand, Aguilar (2014), to give birth to a trans logarithmic cost function, manages to determine for banking the presence of economies of scale. Both at the plant and firm level, showing mixed results in microfinance banking and specialized banks, this through a panel frequently monthly from 2003 to 2010. It turns out that while rural banks have economies of scale at both the plant and signature levels, the financial ones that specialize in micro-finance show economies of scale at both levels, and for banks specializing in micro-finance, the results obtained are dispersed.

Another job is Wheelock and Wilson (2015), where the consolidation of the U.S. banking industry and an overall increase in banks' size has led some policy designers to consider policies that discourage banks from growing, including explicit limits on bank size. However, limits on banks' size could involve economic costs if they prevent banks from achieving economies of scale. This paper presents new estimates

\footnotetext{
${ }^{3}$ Stochastic Frontier Approach is defined as the maximum amount of product that a given firm can produce from a given set of inputs. Technical inefficiency corresponds to differences arising between that theoretical maxim and what the firm actually produces with those inputs. These differences would reflect that the firm has not rated costs at all, for example by opting for inadequate proportions in the relative use of different inputs.
} 
of scale yields for U.S. banks based on non-parametric, local, and linear estimates of bank cost, revenue, and profit functions. They estimate using annual data between 2006 and 2015 to compare yields at scale seven years after the financial crisis and five years after enacting the Dodd-Frank Act with earnings at scale before the crisis. The result is that a high percentage of banks faced rising yields at scale in both years, including most of the ten largest banks, and while income- and profit-scale yields vary more among banks, they find evidence that the four largest banks operate with increasing yields at scale. ${ }^{4}$

On the other hand, Kouki, Park, and Reanult (2014) show a vertically integrated financial production model. In the first stage, commercial banks or insurance companies' activity incorporates some technical and commercial aspects, such as services to depositors or risk securitization through the distribution of insurance contracts. In the second stage, the banks are involved in the intermediation activity. Using a simulation and the indirect least squares method to perform the estimate, they solve two main econometric problems: the breakdown of aggregated data into two vertically integrated production stages and the inconsistency of estimators due to endogeneity and lack of specifications. An application is provided to the French banking industry by using a trans logarithmic cost function, for a sample of 225 banks in France, with data for the year 1990.

Allen and Liu (2007) measured economies of scale for the six largest Canadian banks through a trans logarithmic cost function model through panel data from 1983 to 2003, allowing them to derive relative efficiency measurements and economies of scale. Their results result in them rejecting the assumption of constant yields at scale, finding that technological and regulatory changes have had a significant positive effect on banks' cost structures.

Another work-related to banking is that of Coronado and Vasquez (2001), for the Peruvian banking industry, where they manage to establish that the most rigorous form is the functional form of the costs of the banking system and evaluate, what is the relevant range of products that is, if the industry is operating with increasing, constant, or declining returns on the scale. To achieve this objective, they develop work that refers to the relationship between structure and efficiency but does not delve into the relationship between agents' structure and conduct, so comments on the interest rate and profitability behavior are exclusively referencing. Moreover, while it is true that the banking industry as such has evolved on the concept of Multiple Banking, where-to-one firms the industry's various savings and credit services, that

\footnotetext{
${ }^{4}$ It is a 2010 Act, which promotes financial stability in the United States, through measures that provide transparency and stability in the financial system, dividing the functions of commercial banks and investment banks; In addition, it monitors banking practices and troubled financial institutions to: eliminate problems arising from entities too large to go bankrupt, protect taxpayers from bailout costs of financial institutions, and protect consumers from abusive practices in loans, loans, and mortgages.
} 
is why the authors analyze economies of joint scale, leaving aside elements corresponding to specific product economies and economies of scope or savings to share the asset. Using the panel data methodology to estimate a cost function of the Peruvian banking system through a trans logarithmic functional form, they find that the system operates with increasing yields at a scale of 1.71 , with a cost-product elasticity of 0.58 . So, they can conclude that the banking system has economies of global scale, i.e., as all services' production increases by the same proportion, average production costs will be reduced by allowing gains in productive efficiency.

For Chile, Budnevich, Franken, and Paredes (2001), these authors show the existence of economies of scale, based on estimating the cost function for the banking industry, determining different degrees of economies of scale for banks of different sizes, using monthly data for the years 1989 to 2000, by estimating the cost function in conjunction with the cost-sharing equations, resulting in economies of scale relying on the size of the bank. Also, Escobar (2019), using linear regression by instrumental variables, determines economies of scales in the processing of trades through cards, eventually determining that there is the possibility of new players entering the market. In general, the evidence shows that the determination of economies of scale is achieved by estimating a trans logarithmic model function, which, by applying certain restrictions on parameters, it is possible to transform it into a Cobb-Douglas function, to be used in this work, which will be estimated indirectly from a cost function, which will have as control variables the cost of the production factors and the amounts of transactions made by credit and debit cards.

\section{The Research Model}

The model under which the estimate will be made is based on time-series data and aggregated if the industry has evolved to higher levels of model concentration used as a starting point to Varian (1992). Based on a partial balancing model, the assumptions to consider are the production technology of the electronic means of payment industry can be expressed from a Cobb-Douglas type technology, considering a multiplicative relationship between the factors, with substitution at declining rates between them, so that:

$$
Q_{r}(K, L)=\beta_{0} L^{\beta_{1}} K^{\beta_{2}}
$$

$\mathrm{Q}_{\mathrm{r}}$ is the number of card transactions, represented by the number of transactions made by credit and debit cards, $\mathrm{L}$ is the amount of work factor, $\mathrm{K}$ represents the capital and $\beta_{0}, \beta_{1}$ and $\beta_{2}$ are the coefficients that explain that relationship.

From the expression in (1) and assuming a long-term relationship, it is possible to determine that technology presents increasing yields at scale when the sum of $\beta_{1}$ and $\beta_{2}$ is greater than the unit so that the industry would find the presence of economies of scale, with the existence of these economies, the Average Cost decreases as the product level increases, this to a certain level of product. 
Indirectly it is possible to estimate the coefficients of the expression (1), and it is through the estimation of the cost function that results from a function of the CobbDouglas type, and more specifically, from the marginal cost function, which is expressed in terms of the prices of the production factors and the level of production.

Cost minimization is imposed to obtain an observable relationship and to inform the econometric model. The optimal condition of a representative firm that determines its production level is the level at which market prices $\left(\mathrm{P}_{\mathrm{y}}\right)$ are identical to marginal cost. In this way, there is a direct observation of the marginal cost through the price (commissions) applied by the payment card operator. Thus, you have to the total cost function, which comes from a Cobb-Douglas technology, where it is possible to plant the following cost minimization problem.:

$$
c\left(w, r, Q_{r}\right)=\min _{L, K} w L+r K \quad s / a \beta_{0} L^{\beta_{1}} K^{\beta_{2}}=Q_{r}
$$

From a resolution for restricting the previous $\mathrm{K}$-factor problem, it is possible to raise the minimization problem as follows:

$$
c\left(w, r, Q_{r}\right)=\min _{L, K} w L+r \beta_{0}^{\frac{-1}{\beta_{2}}} Q_{r}^{\frac{1}{\beta_{2}}} L^{\frac{-\beta_{1}}{\beta_{2}}}
$$

Then the first order condition is

$$
w-\frac{\beta_{1}}{\beta_{2}} r \beta_{0}^{\frac{-1}{\beta_{2}}} Q_{r}^{\frac{1}{\beta_{2}}} L^{-\left(\frac{\beta_{1}+\beta_{2}}{\beta_{2}}\right)}=0
$$

Expression from which it is possible to obtain conditional demand for the work factor:

$$
L\left(w, r, Q_{r}\right)=\beta_{0}^{-\left(\frac{1}{\beta_{1}+\beta_{2}}\right)}\left(\frac{\beta_{1} r}{\beta_{2} w}\right)^{\frac{\beta_{2}}{\beta_{1}+\beta_{2}}} Q_{r}^{\frac{1}{\beta_{1}+\beta_{2}}}
$$

This also makes it possible to detach conditional demand for the capital factor:

$$
K\left(w, r, Q_{r}\right)=\beta_{0}^{-\left(\frac{1}{\beta_{1}+\beta_{2}}\right)}\left(\frac{\beta_{1} r}{\beta_{2} w}\right)^{\frac{-\beta_{1}}{\beta_{1}+\beta_{2}}} Q_{r}^{\frac{1}{\beta_{1}+\beta_{2}}}
$$

where you can express the cost function as:

$$
C\left(w, r, Q_{r}\right)=w L\left(w, r, Q_{r}\right)+r K\left(w, r, Q_{r}\right)
$$

Therefore, replacing it is possible to determine the following expression as a cost function:

$$
C(w, r, Q r)=M w^{\left(\frac{\beta_{1}}{\left(\beta_{1}+\beta_{2}\right)}\right)} r^{\left(\frac{\beta_{2}}{\left(\beta_{1}+\beta_{2}\right)}\right)} Q r\left(\frac{1}{\left(\beta_{1}+\beta_{2}\right)}\right)
$$


Where $\mathrm{C}$ is the total cost, $\mathrm{w}$ represents the cost of the work, $\mathrm{r}$ is the actual interest rate, and $\mathrm{Q}_{\mathrm{r}}$ is the level of transactions made by electronic means of payment, which in this case is represented by the number of transactions made by electronic means of payment $\left(\mathrm{Q}_{\mathrm{r}}\right)$, and the $\mathrm{M}$ factor is a constant equal to:

$$
\beta_{0}^{\left(\frac{-1}{\left(\beta_{1}+\beta_{2}\right)}\right)}\left[\left(\frac{\beta_{1}}{\beta_{2}}\right)^{\left(\frac{\beta_{2}}{\left(\left(\beta_{1}+\beta_{2}\right)\right)}\right)}+\left(\frac{\beta_{1}}{\beta_{2}}\right)^{\left(\frac{-\beta_{1}}{\left(\left(\beta_{1}+\beta_{2}\right)\right)}\right)}\right]
$$

With these expressions it is possible to determine that the commissions applied to transactions are equal to the marginal cost, which is obtained from the first order conditions, and that it is represented by:

$$
\begin{aligned}
& M C=\frac{\partial C T(w, r, Q r)}{\partial Q r} \\
& \left(\frac{1}{\left(\beta_{1}+\beta_{2}\right)}\right) M w^{\left(\frac{\beta_{1}}{\left(\beta_{1}+\beta_{2}\right)}\right)} r^{\left(\frac{\beta_{2}}{\left(\beta_{1}+\beta_{2}\right)}\right)} Q r^{\left(\frac{1-\left(\beta_{1}+\beta_{2}\right)}{\left(\beta_{1}+\beta_{2}\right)}\right)}
\end{aligned}
$$

When considering the optimal condition for the case of a highly concentrated market such as the payment methods market through cards. In this case the price is weighted by a factor that measures the monopoly power of the representative signature, the estimate of which is found in Bresnahan's work (1982). This factor alters the average price level to be observed in the industry, but not the estimation of the exponents of the function.

$$
\begin{aligned}
& P\left(\frac{1}{\left(1-\eta_{p}\right)}\right)=M C= \\
& \left(\frac{1}{\left(\beta_{1}+\beta_{2}\right)}\right) M w^{\left(\frac{\beta_{1}}{\left(\beta_{1}+\beta_{2}\right)}\right)} r^{\left(\frac{\beta_{2}}{\left(\beta_{1}+\beta_{2}\right)}\right)} Q r^{\left(\frac{1-\left(\beta_{1}+\beta_{2}\right)}{\left(\beta_{1}+\beta_{2}\right)}\right)}
\end{aligned}
$$

That is why in this work interest is focused on the exponent that accompanies the level of production, because it reflects the type of performance at scale presented by the processing of transactions by payment cards, in this sense it is essential to know the sign of the exponent.

For the purpose of simplifying, it is possible to re-parameterize the expression (4), performing the following steps, the factor representing market power $\left(\frac{1}{\left(1-\eta_{p}\right)}\right)$ by $\kappa$ , the constant $\left(\frac{1}{\left(\beta_{1}+\beta_{2}\right)}\right) M$ by $\alpha_{0}$, the exponent accompanying the salary $\left(\frac{\beta_{1}}{\left(\beta_{1}+\beta_{2}\right)}\right)$ by $\alpha_{1}$, the exponent accompanying the interest rate $\left(\frac{\beta_{2}}{\left(\beta_{1}+\beta_{2}\right)}\right)$ by $\alpha_{2}$, and the exponent associated with the level of production $\left(\frac{1}{\left(\beta_{1}+\beta_{2}\right)}\right)$ by $\alpha_{3}$, so that the expression (4) remains as follows:

$$
P y k=\alpha_{0} w^{\alpha_{1}} r^{\alpha_{2}} Q^{\alpha_{3}}
$$


Clearing

$$
P y=\left(\frac{\alpha_{0}}{\kappa}\right)\left(w^{\alpha_{1}} r^{\alpha_{2}} Q^{\alpha_{3}}\right)
$$

Then applying logarithm to (6):

$$
\ln P y=\ln \alpha_{0}-\ln \kappa+\alpha_{1} \ln w+\alpha_{2} \ln r+\alpha_{3} \ln Q
$$

Remaining the model to be estimated as follows:

$$
\begin{aligned}
\ln P y_{i t}=\ln \gamma_{0} & +\gamma_{1} \ln w_{i t}+\gamma_{2} \ln r_{i t} \\
& +\gamma_{3} \ln Q_{i t}+\text { dummy }+\varepsilon_{i t} \quad \text { with } i=1,2
\end{aligned}
$$

Therefore, in this model presented in (8), $\gamma_{0}=\ln \alpha_{0}-\ln \kappa$, and the coefficient $\gamma_{3}=\left(\frac{1-\left(\beta_{1}+\beta_{2}\right)}{\left(\beta_{1}+\beta_{2}\right)}\right)$, which corresponds to the exponent that accompanies the production level. Particular attention should be paid to this coefficient, because if its sign is negative, it indicates that the technology used has increasing yields at scale, since $\beta_{1}+\beta_{2}>1$. If it has a positive sign, the technology will show yields at a decreasing scale, and if statistically equal to zero, it suggests returns at a constant scale. In the case of the error term, the white noise type is assumed. In addition, the model incorporates a dummy variable, a variable that seeks to capture the seasonal effects of the months of January and February, which captures the fewest transactions carried out for the purpose of the summer period.

\section{Data and Results}

The definition of the variables observed for the period January 2013 to May 2020 is: $\mathrm{P}_{\mathrm{y}}$, the commission received by banks in card transactions, the value obtained from the Superintendency of Banks and Financial Institutions, which is used as a proxy variable of the prices determined by the network to merchants that accept these means of payment; Q, total transactions carried out by credit and debit cards, data obtained from statistical bases of the Superintendency of Banks and Financial Institutions; $w_{t}$, remuneration index of the Chilean economy, prepared by the National Statistical Institute; $r_{t}$, the interest rate of the Central Bank Bonds at five years; all these variables are expressed in terms of logarithms. It should be noted that using a proxy variable for the prices and length of the series can cause certain limitations to the model.

Due to the characteristics of the estimated model, the variables were incorporated in terms of the logarithm. It is in this way that the unit root test was applied. This test allows to identify the presence of a trend, intercept, and constant variance or not. In this case, the series has constant variance when, in absolute terms, the calculated Dickey-Fuller (DFA) statistic is greater than the tabulated one. The result is presented in Table 1 and Table 2 below.

The model estimated through panel data is considered to control the possible 
existence of self-correlation of waste and unit root in the variables considered. In this sense, it was justified to incorporate variables into logarithm, both the variable wages and interest rate. In the original model of this estimate, I present that the individual coefficients are different from zero, according to the $t$ statistic and the statistic F.

The coefficient accompanying production was different and less than zero, suggesting that the card processing process has increasing returns on a scale, implying that average costs suggest a declining trajectory as the production level increases, which has a strong implication in terms of industry competitiveness. According to the estimated model, the sum of product - work and product - capital elasticities, production is increased by $14,4 \%$, when production factors are increased by $1 \%$. This shows that the industry has rising-scale yields. According to the expression (2), analyzing algebraically in individual terms, the cost-work elasticity turned out to be 14,123 , and the cost-capital was 0,279 .

Table 1. Card Operations Processing Industry. Statistic Used (Jan 2008-May 2020) Variable

\begin{tabular}{|c|c|c|c|c|}
\hline & $\begin{array}{l}\text { Price } \\
\text { (US\$) }\end{array}$ & $\begin{array}{l}\text { Operations } \\
\text { (Nro) }\end{array}$ & $\begin{array}{l}\text { Nominal } \\
\text { Remuneration } \\
\text { Index (Base 2016 = } \\
\text { 100) }\end{array}$ & $\begin{array}{l}\text { Interest Rate } \\
\text { 5-Year Bonds } \\
\text { in UF } \\
\text { Tendered by } \\
\text { the Central } \\
\text { Bank of Chile }\end{array}$ \\
\hline Average & 0.24 & $65,532,181$ & 101.71 & $1.13 \%$ \\
\hline Minimum & 0.01 & $11,217,375$ & 83.31 & $-0.67 \%$ \\
\hline Maximum & 1.09 & $187,436,692$ & 120.06 & $2.69 \%$ \\
\hline Standard Desv. & 0.26 & $44,624,573$ & 10.84 & $0.76 \%$ \\
\hline
\end{tabular}

Source: Elaboration based on statistics from the Central Bank of Chile (www.bcentral.cl).

Table 2. Result of Unit Root Testing in Model Variables

\begin{tabular}{llll}
\hline Variable & $\begin{array}{l}\text { Dickey-Fuller } \\
\text { Augmented } \\
\text { Statistician } \\
\text { (DFA) }\end{array}$ & $\begin{array}{l}\text { DFA Critical Value } \\
\mathbf{1 \%}\end{array}$ & H0: Presence of unit root \\
\hline LnPt & -6.14 & -4.066 & Rejects hypotheses at $1 \%$ \\
LnQt & -4.565 & -4.066 & Rejects hypotheses at $1 \%$ \\
Lnrt & -7.044 & -4.066 & Rejects hypotheses at $1 \%$ \\
Lnwt & -1.748 & -4.066 & Accept hypothesis
\end{tabular}

Source: Own elaboration.

The above results suggest that the use of factors in the industry is in logical sections, according to production theory, i.e., the area of concave production function where the firm's profit is positive. The above case is characterized by the product-factor elasticity being less than one and more significant than 0, as Varian (1992) indicated. On the other hand, given the product elasticities - factor found, it can be said that the process is intensive in the use of capital. 
According to the above results, the industry presents economies of scale since production costs vary by a decrease of 4.32 and correspond to the reciprocation of the sum of product-factor elasticities. This implies that when production increases by $1 \%$, the total production cost decreases by $4,32 \%$, thus clearly lowering the average cost. Indeed, the natural process that underpins the behavior of trading processing is undoubtedly related to the sharp increase in the number of cards held by users or cardholders: as well as the increase in the volume of transactions carried out with this means of payment in recent years, which in addition to the fall in the cost of capital, contributes to this process showing or presenting economies of scale.

With the results obtained and found in Table 3, a model was set up that seeks to simulate the long-term behavior of the average cost in processing operations through credit and debit cards to discuss aspects related to the industry's competitiveness. Thus, considering equation (2), coefficient estimates and a hypothesis about the value of parameter $\mathrm{M}$, was obtained as a total cost equation for the processing of such transactions of:

$$
C=M w^{0,28} r^{0,72} Q_{r}^{-4.32}
$$

Assuming component $\mathrm{M}$ as a numerary and using the average value of the price of factors $\mathrm{w}$ and $\mathrm{r}$ for the period from January 2013 to May 2020, the Average Cost $\left(\mathrm{C} / Q_{r}\right)$, is estimated, for the different levels in the order of magnitude of market prices. The result can be seen in Figure 4, and it is apparent that the long-term AC is around US $\$ 1 \times 10^{-46}$ per transaction, this as the level of transactions with these means of payment increases:

Table 3. Result of Model Estimate (Period January 2013 - May 2020)

\begin{tabular}{|c|c|c|c|c|}
\hline Equation & Coefficient & Std. Err. & t - Statistic & $\mathbf{P}$ \\
\hline \multicolumn{5}{|l|}{$\ln p$} \\
\hline $\operatorname{lnq}$ & -4.315468 & 1.0400330 & -4.15 & 0.000 \\
\hline $\ln w$ & 14.123700 & 3.9304720 & 3.59 & 0.000 \\
\hline $\ln r$ & 0.279593 & 0.1404038 & 1.99 & 0.046 \\
\hline dummy & -1.671178 & 0.1160769 & -14.40 & 0.000 \\
\hline constante & 15.989530 & 3.0189240 & 5.30 & 0.000 \\
\hline sigma_u & 1.317784 & & & \\
\hline sigma_e & 0.516843 & & & \\
\hline rho & 0.866682 & & & \\
\hline R-sq: within & 0.617800 & & $\mathbf{n}$ & 158 \\
\hline between & 1.000000 & & Groups & 2 \\
\hline \multirow[t]{2}{*}{ overall } & 0.755900 & & Obs by groups & 79 \\
\hline & & & Wald chi2(4) & 243.500000 \\
\hline $\operatorname{Corr}\left(\mathbf{u} \_\mathbf{i}, \mathbf{X}\right)$ & 0.000000 & & Prob > chi2 & 0.000000 \\
\hline$F(1,152)$ & 7.93 & & Prob > F & 0.005500 \\
\hline
\end{tabular}

Source: Own creation. 


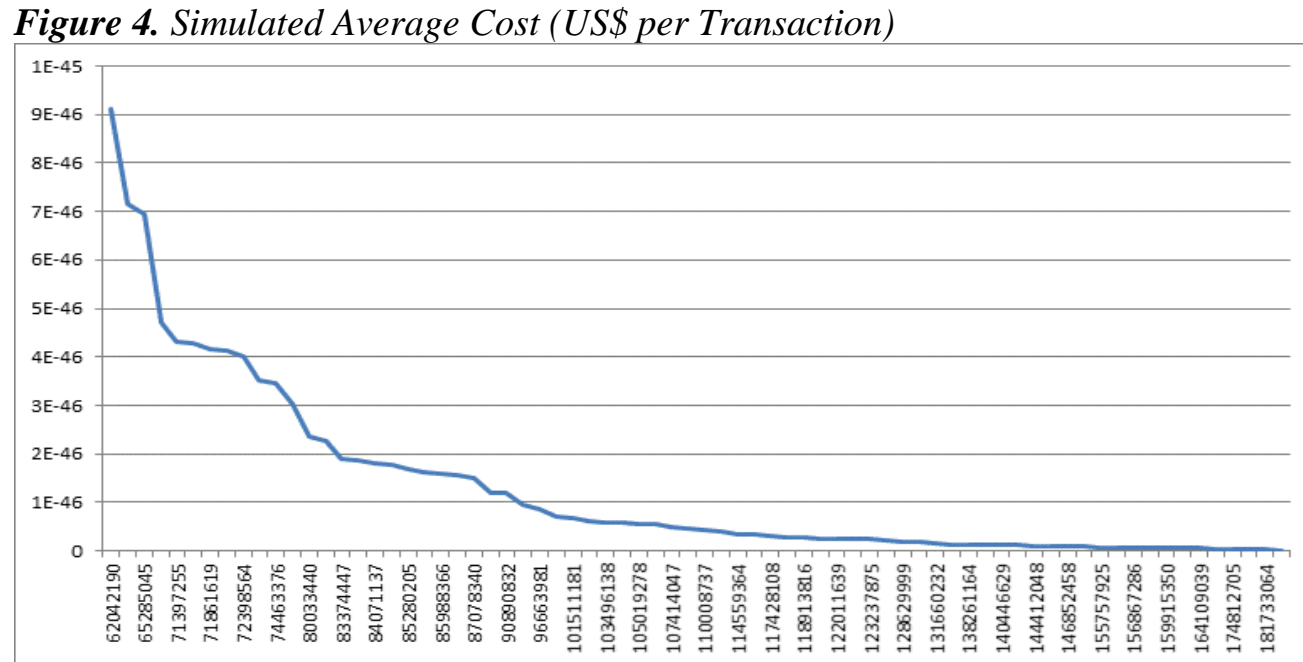

Source: Own elaboration.

\section{Conclusions}

Between January 2013 and May 2020, the credit and debit card payment processing industry presented returns on a growing scale, this under the assumption of industryleading technology, which can be described through a Cobb-Douglas production function, and which the firm maximizes profit in the market, which has the characteristic of being imperfectly competitive. Product elasticity - the estimated scale of 14,123 .

During this same period, this industry presented economies of scale, given the costproduct elasticity of -4.32 . The estimate made revealed that the factors are in optimal quantities, according to the theory of production, and that the production process is more intensive in the use of capital about the work factor. In a simulation of the average cost behavior in processing such operations, under an increase in transaction levels with these means of payment, this cost converges at an order level of US $\$ 1 \times 10$ 46 for each of the transactions.

Finally, it is possible to determine that this type of firm dedicated to the processing of card operations can continue to reduce their processing costs, but it also generates the spaces to enter new players in the sector, especially firms related to Fintech. This work leaves open the possibility of extending it to an estimate of the presence of economies of scope, as well as to see the existence of a cartel by the bank, which could have been coordinated through the network, and have been disjointed at the time one of the shareholders decides to leave the network's ownership.

\section{References:}

Aguilar, G. 2014. Economías de escala en la industria microfinanciera. El Trimestre Económico, 81(323), 747-778. 
Akkemik, A. 2009. Cost function estimates, scale economies and technological progress in the Turkish electricity generator sector. Energy Policy, 37, 204-2013.

Aleaifar, M., Farsi, M., Filippini, M. 2014. Scale Economies and optimal size in the Swiss gas distribution sector. Energy Policy, 65, 86-93.

Allen, J., Liu, Y. 2007. Efficiency and Economies of Scale of Large Canadian Banks. The Canadian Journal of Economies, 40(1), 225-244.

Amir, R. 2002. Market Structure, Scale Economies and Industry Performance. Discussion paper. University of Copenhagen. Institute of Economics.

Beccalli, E., Anolli, M., Borello, G. 2015. Are European banks too big? Evidence on economies of scale. Journal of Banking \& Finance, 58, 232-246.

Bresnahan, T. 1982. The oligopoly solution concept is identified. Economics Letter, 10, 8791.

Budnevich, L., Franken, H., Paredes, R. 2001. Economías de escala y economías de ámbito en el sistema bancario chileno. Economía Chilena, 4(2).

Cmf. 2020. Retrieved from: www.cmf.cl.

Coronado, J., Vásquez, J. 2001. Economías de Escala Globales en la Industria Bancaria del Perú: Modelo de Datos de Panel. Instituto Peruano de Economía. Retrieved from: https://www.ipe.org.pe/portal/economias-de-escala-globales-en-la-industriabancaria-del-peru-modelo-de-datos-de-panel/.

Elmostrador. 2018. Retrieved from:

Escobar, G. 2019. Estimación de Economías de Escala en el Mercado de Tarjetas de Pago. Multidisciplinary Business Review, 12(2), 55-66.

Garron, I., Rocabado, T. 2016. Economías de Escala y Eficiencia en la banca boliviana: el efecto en la especialización del crédito. Revista de Análisis, 25141-25190. https://www.elmostrador.cl/mercados/2018/10/11/fin-del-contrato-entresantander-y-transbank-remece-el-monopolio-del-mercado-del-pago-electronico/.

Kim, Y. 1986. Economies of Scale and Economies of Scope in Multiproduct Financial Institution: Further Evidence from Credit Union. Journal of Money, Credit and Banking, 18(2), 220-226.

Kouki, M., Park. S., Renault. 2014. Estimating scale economies in financial intermediation: a doubly indirect interference". Journal of Productivity Analysis, 41(3), 351-365.

Latercera. 2020. Retrieved from: https://www.latercera.com/pulso/noticia/santander-podriarecaudar-mas-17-mil-millones-venta-participacion-transbank/453526/.

MacDonald, J., Ollinger, M. 2000. Scale Economies and Consolidation in Hog Slaughter. American Journal of Agricultural Economics, 82, 334-346.

Marchant, R. 2007. Estimación de economías de escala en la industria de la carne de cerdo en Chile. Agricultura Técnica, 67(3), 292-299.

Murray, J., White, R. 1983. Economies of Scale and Economies of Scope in Multiproduct Financial Institutions: A Study of British Columbia Credit Unions. The Journal of Finance, 38(3), 887-902.

Ollinger, M., MacDonald, J., Madison, M. 2005. Technological Change and Economies of Scale in U.S. Poultry Processing. American Journal of Agricultural Economics, 87(1), 116-129.

Panzar, J. 1989. Technological Determinants of Firm and Industry Structure. In Schmalensee R. Handbook of Industrial Organization, 1.

Rochet, J.C., Tirole, J. 2002. Cooperation among competitors: Some economics of payment card associations. RAND Journal of Economics, 33(4), 1-22.

Varian Hal. 1992. Análisis microeconómico. $3^{\circ}$ Edición. Antoni Bosch Editores.

Wheelock, D.C., Wilson, P.W. 2015. The Evolution of Scale Economies in U.S. Banking. Working Papers, 21, Federal Reserve Bank of St. Louis. 